\title{
Optimal Configuration of Wind Farms in Radial Distribution System Using Particle Swarm Optimization Technique
}

\author{
Mahesh Kumar ${ }^{1}$, Bhagwan Das ${ }^{2}$, Perumal Nallagownden ${ }^{3}$, Irraivan Elamvazuthi ${ }^{4}$, Sadia Ali Khan ${ }^{5}$ \\ ${ }^{1,3,4}$ Department of Electrical and Electronics Engineering, Universiti Teknologi PETRONAS Seri Iskandar, Perak Darul \\ Ridzuan, Malaysia \\ ${ }^{2}$ Department of Electronic Engineering, Quaid-e-Awam University of Engineering and Technology, Sindh Pakistan \\ ${ }^{5}$ Department of Computer Science, University of Karachi, Sindh, Pakistan
}

\begin{tabular}{l}
\hline \hline Article Info \\
\hline Article history: \\
Received Feb 01, 2018 \\
Revised Apr 11, 2018 \\
Accepted Apr 29, 2018 \\
\hline
\end{tabular}

Keywords:

Distribution system

Optimal location and sizing

Particle Swarm Optimization

(PSO)

Wind assessment

\begin{abstract}
Recently, a wide range of wind farm based distributed generations (DGs) are being integrated into distribution systems to fulfill energy demands and to reduce the burden on transmission corridors. The non-optimal configuration of DGs could severely affect the distribution system operations and control. Hence, the aim of this paper is to analyze the wind data in order to build a mathematical model for power output and pinpoint the optimal location. The overall objective is minimization of power loss reduction in distribution system. The five years of wind data was taken from $24^{\circ} 44^{\prime} 29^{\prime \prime}$ North, $67^{\circ}$ 35' 9" East coordinates in Pakistan. The optimal location for these wind farms were pinpointed via particle swarm optimization (PSO) algorithm using standard IEEE 33 radial distribution system. The result reveals that the proposed method helps in improving renewable energy near to load centers, reduce power losses and improve voltage profile of the system. Moreover, the validity and performance of the proposed model were also compared with other optimization algorithms.
\end{abstract}

Copyright $@ 2018$ Institute of Advanced Engineering and Science. All rights reserved.

\section{Corresponding Author:}

Mahesh Kumar,

Department of Electrical and Electronics Engineering,

Universiti Teknologi PETRONAS,

Seri Iskandar, Perak Darul Ridzuan, Malaysia.

Email: rathii.mahesh@gmail.com

\section{INTRODUCTION}

The demand of electricity is increased recently due to urbanization and industrial revolution. In early ages, electric demand was mainly fulfilled by fossil fuel based generation. Now a days, fossil fuel based power generation leaving a serious threat to environment. It releases large amount of greenhouse gas emissions, which further increases the global temperature and eventually results natural disasters (like. floods, earth-quick etc.). In order to cater this problem, the renewable energy based power generation in distribution system is of great interest. Different types of renewable energies are available, which are inexhaustible and freely available in the nature. The electrical power generation system is large and centralized; it is delivering bulk power to the national grids and even international grids. Currently it is operating optimally, adding more capacity to sustain power will increase the cost and deteriorates the environmental standards. On the other hand, the small power generation called distributed generation (DG) from renewable energies in distribution system will settled the problems of centralized electrical power generation. There are number of benefits with DG integration in distribution system, firstly it is near to the load center hence reduces the electric current from transmission system. Electric power locally to load ends will improves the power quality and reliability. The DG has numerous advantages in terms of technical, economic and environmental [1]-[3] such as: 
a. It improves the voltage profile.

b. Reduce power loss.

c. Enhance the voltage stability and increases the system's capacity.

d. Improve reliability and power quality.

e. Reduce transmission line congestion hence reduce investment deferral.

f. Reduce fossil fuel dependency hence reduce GHG emissions.

Power output from wind turbine is mainly depends on wind speed and complete knowledge of wind characteristics [4]. The average monthly and yearly wind speeds gives the knowledge about suitability of wind location. The wind speed within the range of $4 \mathrm{~m} / \mathrm{s}$ to $6 \mathrm{~m} / \mathrm{s}$ classifies as moderate [5] and according to European wind energy union, wind speed with range of $6.5 \mathrm{~m} / \mathrm{s}$ is considered as approximately good, $7.5 \mathrm{~m} / \mathrm{s}$ is considered as good and $8.5 \mathrm{~m} / \mathrm{s}$ is very good at a given height [6]. China, Germany, and USA are top three countries which are utilizing 45.1 percent, 10.2 percent and 9.4 percent respectively [7].

Nowadays, the wind turbines more and more are integrated in distribution system for nearest power delivery and to fulfill energy needs. Hence to get maximum remuneration from renewable DGs and to increase the suitable environment, it should be properly configured. Many authors havr researched on same area such as voltage profile improvement with wind based DG in distribution. The author [8-9] uses convolution technique with probabilistic model of wind based DG and results are discussed with expected value of voltage on loads. The short-term forecasting model with solar PV DG by is proposed by [10]. The effects of high wind based DG penetrating in distribution system on voltage profile is researched by [11]. The author concludes that High wind based DG will changes the system voltage, however with proper dispersion level, this drawback can be overcome. Wind, solar and load with probabilistic model in distribution system is analyzed by [12]. The author uses Monte Carlo based probabilistic load flow simulation to reduce power losses and increase the voltage profile of the system. Probabilistic model for investment deferral in distribution system is analyzed by [13]. The author uses combined heat and power (CHP), solar and wind based DG along with probabilistic load generation. Furthermore author also concludes that DG(s) can defer the investment with increasing load growth. Optimal size of different types of DG using analytical method for optimal placement and sizing is described by [14]. Linear programming method is used for optimal DG placement and to gather maximum amount of energy, considering financial and technical constraints [15-16]. Power loss reduction and customer reliability improvement using DG in distribution system has been proposed by [17]. The probabilistic generation-load model with its all operating condition and probabilities has been accommodated in deterministic model. Author used the non-linear programming method to solve the optimal DG placement and sizing problem with only wind [18] and all DG types [19].

This study offers an advancement on wind energy potential. Hourly, monthly and yearly mean and standard deviations were utilized to form probability distributions. Furthermore, these probabilities were explored to identify power generation output from wind turbines and finally these wind farms were connected to radial distribution systems with optimal locations so that maximum power losses could be curtailed. The PSO optimization technique was utilized to pinpoint optimal locations in the distribution system.

This paper is organized as Section 2 presents the problem formulation for power loss reduction with system constraints. Section 3 presents wind speed model. Section 4 presents the simulation results of wind speed data and its results. Section 5 presents the optimization technique and simulation results and discussion for optimal location of wind farm with different case studies. Section 6 presents the conclusion.

\section{PROBLEM FORMULATION)}

In this paper main objective function is set as minimization of real power loss of the radial distribution system with following constraints. The objective function can be mathematically described as in Equation 1.

$$
\min \mathrm{f}=\min \left(\mathrm{T}_{\text {loss }}\right)
$$

Where, Tloss is the active power losses of the radial bus system.

Equality constraints:

The equality and inequality constraints are given in Equation (2-5).

The bus real and reactive power is limited to:

$$
\begin{aligned}
& \mathrm{P}_{\mathrm{DG}, \mathrm{M}}=\mathrm{P}_{\mathrm{Loss}}+\sum \mathrm{P}_{\mathrm{D}, \mathrm{M}} \\
& \mathrm{Q}_{\mathrm{DG}, \mathrm{M}}=\mathrm{Q}_{\mathrm{Loss}}+\sum \mathrm{Q}_{\mathrm{D}, \mathrm{M}}
\end{aligned}
$$


Where $P_{D G, M}$ and $P_{D G, M}$ are the real and reactive power injection by $D G$ at bus $M . \Sigma P_{D, M}$ and $\Sigma P_{D G, M}$ are the total real and reactive power at bus $\mathrm{M}$. According to these constraints the real and reactive power injection at bus $\mathrm{M}$ must be equal to actual real power demand at that node and power losses of that node.

Inequality constraints:

Position of DG:

$$
2 \leq \mathrm{DG} \text { position } \leq \text { nbuses }
$$

Voltage at load bus

$$
\mathrm{V}_{\mathrm{M}}^{\min } \leq \mathrm{V}_{\mathrm{M}} \leq \mathrm{V}_{\mathrm{M}}^{\max }
$$

$\mathrm{V}_{\mathrm{M}}^{\min }$ and $\mathrm{V}_{\mathrm{M}}^{\max }$ are minimum and maximum voltage at bus $\mathrm{M}$. The power loss, voltage and other parameters are found using backward forward load flow analysis, detail given in [20]

\section{WIND SPEED MODEL}

\subsection{Wind Probability Distribution}

The wind speed data are modeled by probability distributions. The purpose of these distribution are to examine the frequency of wind speed data or in other terms that a particular wind speed falls how much in during a time period (in a month or in a year). In literature many probability distributions are cited, like normal distribution, lognormal distribution, weibull and Rayleigh distributions. Among all distributions, the Weibull probability distribution functions is highly used due to its accurate and adequate specification for wind data analyzing.

$$
f(v)=\left(\frac{k}{c}\right)\left(\frac{v}{c}\right)^{k-1} \exp \left[-\left(\frac{v}{c}\right)^{k}\right]
$$

where $f(v)$ is the probability of wind speed, $k$ is shape parameter, $c$ is scale parameter.

\subsection{Wind Power Generation Model}

The power output from wind turbine depends primarily on wind speed and it varies in non-linear relation with wind speed. Figure.1. shows the graph between wind speed versus its probability distribution and output power curve of wind turbine. From Figure 1, it can be seen that the output power start at wind turbine minimum cut in speed. As wind speed increases till rated speed output power increases nonlinearly [22], then after remains constant till wind speed reaches at wind turbine cut-out stage. Interestingly beyond cut-out stage even speed increases, the wind turbine needs to shut down for retaining the wind turbine mechanical strength and stability.

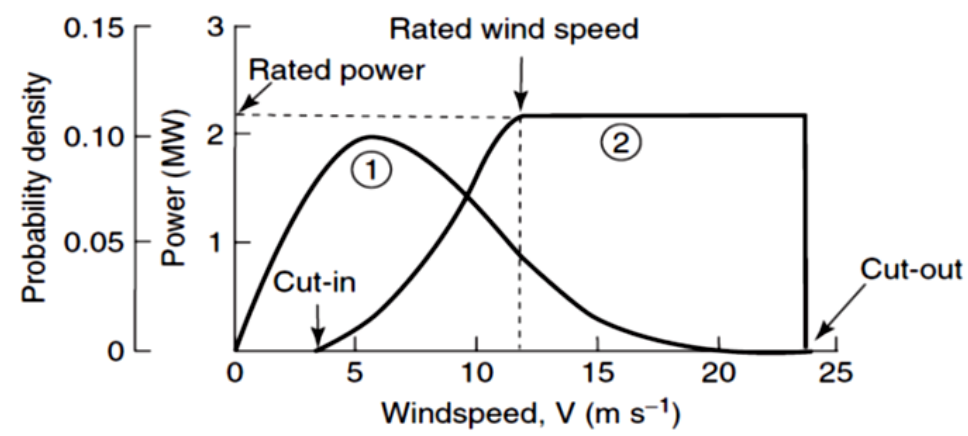

Figure 1. Wind speed versus Probability distribution and wind speed versus electrical output power

Mathematically output power from wind turbine can be expressed as: 


$$
P_{\text {wind,output }}=\left\{\begin{array}{c}
00 \leq v_{a w} \leq v_{c i} \\
P_{\text {rated }} * \frac{v_{a w}-v_{c i}}{v_{r}-v_{c i}} v_{c i} \leq v_{a w} \leq v_{r} \\
P_{\text {rated }} v_{r} \leq v_{a w} \leq v_{c o} \\
0 v_{c o} \leq v_{a w}
\end{array}\right.
$$

where $P_{\text {rated }}$ is the rated output power from wind turbine, $v_{a w}$ is the average wind speed,$v_{c i}$ is the cu-in speed, $v_{r}$ is the rated speed and $v_{c o}$ is the cut-out speed. where $P\left(G_{w}\right)$ is the power generation of particular state, vw1 and vw2 are the wind speed states.

\section{SIMULATION RESULTS FOR WIND SPEED DATA}

In this paper, five years of wind speed data was analyzed using MATLAB 2015a software. Each minute by minute data of five years were further divided into yearly, monthly, and hourly basis. The Weibull and Rayleigh probability density function (PDF) was designed for each month and year. The hourly, monthly, and yearly data was utilized to form the mean and standard deviation. Finally, the power output curve of wind turbine from the manufacturer was utilized to identify power output from wind turbines at selected sites.

\subsection{Yearly and Monthly Wind Speed}

Figure 2 shows the annual wind speed of every minute from the year, 2003 to 2007. It can be seen that in 2006 and 2007, the wind speed remained high as compared to 2003, 2004 and 2005. The overall mean wind speed of each year remained at more than 5 meters per second. Figure 3 shows the monthly mean wind speed of each year. It can be observed that in each year, from April to September, wind speed remained in the range of 4-9 meters per second, whereas the highest wind speed was in the month of August, 2004

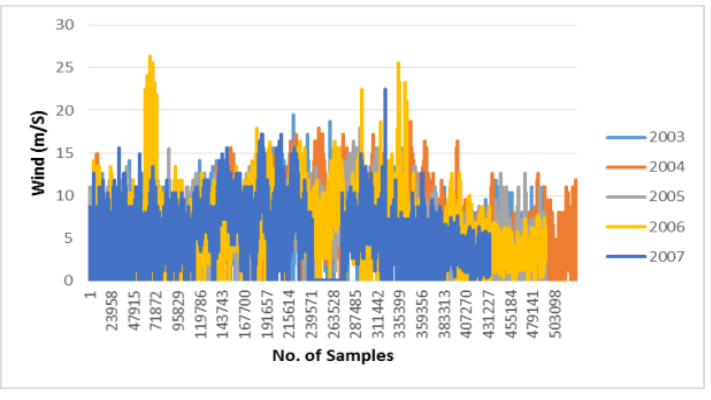

Figure 2. No. of wind speed samples of year 2004 to 2007

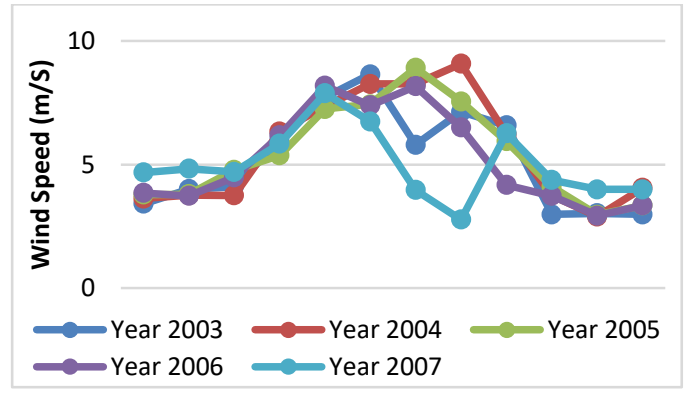

Figure 3. Mean of monthly wind speed of year 2004 to 2007

\subsection{Average Wind Speed and Statistical Parameter}

The average wind speed was taken from the sum of wind speeds of each year to the total number of wind samples of that year. Figure 4 records the average wind speed of each year. It also shows that in 2004 and 2006, the average wind speed remained more than 5.6 meters per second which was higher than all the other years.

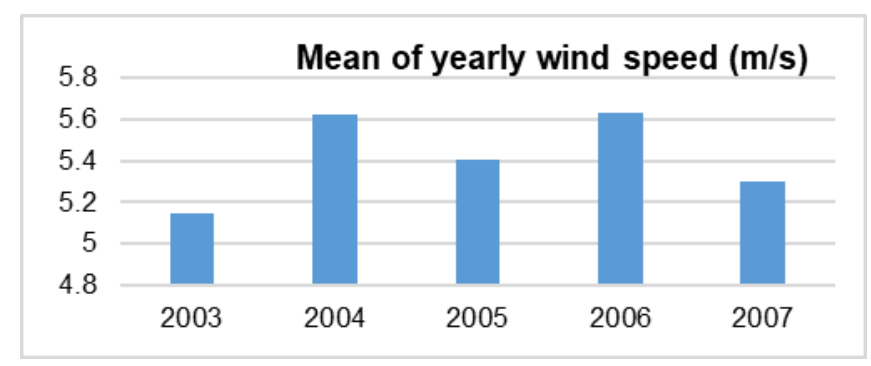

Figure 4. Mean of yearly wind speed of year 2004 to 2007 
Table 1 shows the statistical parameters of wind speed, along with the mean or average wind speed of each year, which is derived from Equation 6.

Table 1. The Statistical Wind Parameters

\begin{tabular}{cccccc}
\hline Parameters & 2003 & 2004 & 2005 & 2006 & 2007 \\
\hline Avg & 5.1461 & 5.6200 & 5.4062 & 5.634 & 5.2996 \\
std & 3.3562 & 3.2332 & 2.9831 & 3.226 & 3.1859 \\
K & 1.5906 & 1.8228 & 1.9073 & 1.8324 & 1.7378 \\
C & 5.7366 & 6.3234 & 6.0931 & 6.3414 & 5.9481 \\
Vmp & 3.0774 & 4.0874 & 4.1273 & 4.1226 & 3.6333 \\
Vmax & 7.7951 & 8.0380 & 7.6002 & 8.0427 & 7.7261 \\
\hline
\end{tabular}

\subsection{Electrical Power Output from Wind Turbines}

The electrical output power from wind turbines depends on the wind turbine model and wind speed data. Equation (7) is used to calculate the yearly output power and energy from Enercon-65 wind turbine. The height of the wind turbine is set at 80 meters using the power law formula. The other parameters of this wind turbine are $v_{c i}=4 \mathrm{~m} / \mathrm{s}, v_{r}=13 \mathrm{~m} / \mathrm{s}, v_{c o}=25 \mathrm{~m} / \mathrm{s}$ and $P_{\text {rated }}=1.5 * \mathrm{e}^{6}$ watts. Figure 5 shows the wind turbine power curve, the total energy output of this turbine is 562.476 kiloWatts.

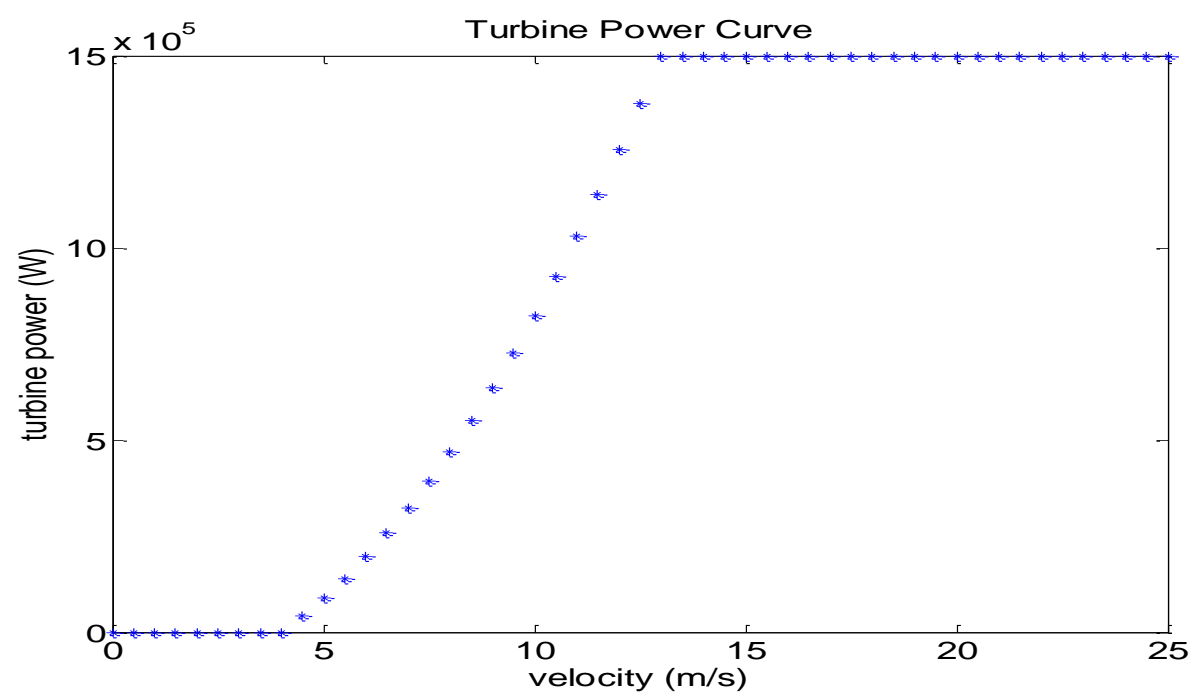

Figure 5. Wind turbine power curve

\section{SIMULATION RESULTS AND DISCUSSION}

Optimal placement of wind farm was carried out using PSO optimization technique. The PSO algorithm is a stochastic optimization technique introduced by [23]. This algorithm is basically inspired by social behavior of living things such as birds flocking and fish schooling. Suppose v and S in search space are the velocity and position of particle $\mathrm{i}$. So $\mathrm{i}^{\text {th }}$ particle position can be written as $\left(S_{i}=S_{i, 1}, S_{i, 2} \ldots \ldots S_{i, d}\right)$, where $\mathrm{d}$ is the dimensional space of particle. The previous best $\mathrm{i}^{\text {th }}$ particle position will be $\left(\right.$ Pbest $_{i}=$ Pbest $_{1}$, Pbest $_{2} \ldots \ldots$ Pbest $\left._{i, d}\right)$. The best particle among the all, will be gbest and the velocity of particle i can be represented by $\left(V_{i}=V_{i, 1}, V_{i, 2} \ldots \ldots V_{i, d}\right)$. Each particle's velocity closes to pbest and gbest is calculated by Equation (8). Each particle's current position is updated by Equation (9). Figure 6, shows the complete flow chart of proposed method.

$$
\begin{aligned}
& \left.v_{i d}^{k+1}=\omega \times v_{i d}^{k}+c_{1} \times \operatorname{rand}() \times\left(\text { pbest }_{i d}-v_{i d}^{k}\right)+c_{2} \times \operatorname{rand}_{(}\right) \times\left(\text {gbest }_{d}-v_{i d}^{k}\right) \\
& S_{i d}^{k+1}=S_{i d}^{k}+v_{i d}^{k+1}, i=1,2, \ldots . . n, d=1,2 \ldots, m
\end{aligned}
$$


The IEEE 33 radial distribution system was conducted using the proposed method as shown in Figure 7. The total real and reactive power demand on this distribution system is $3.715 \mathrm{MW}$ and 2.300 MVAr, respectively. The bus and line parameters are taken from [24-25]

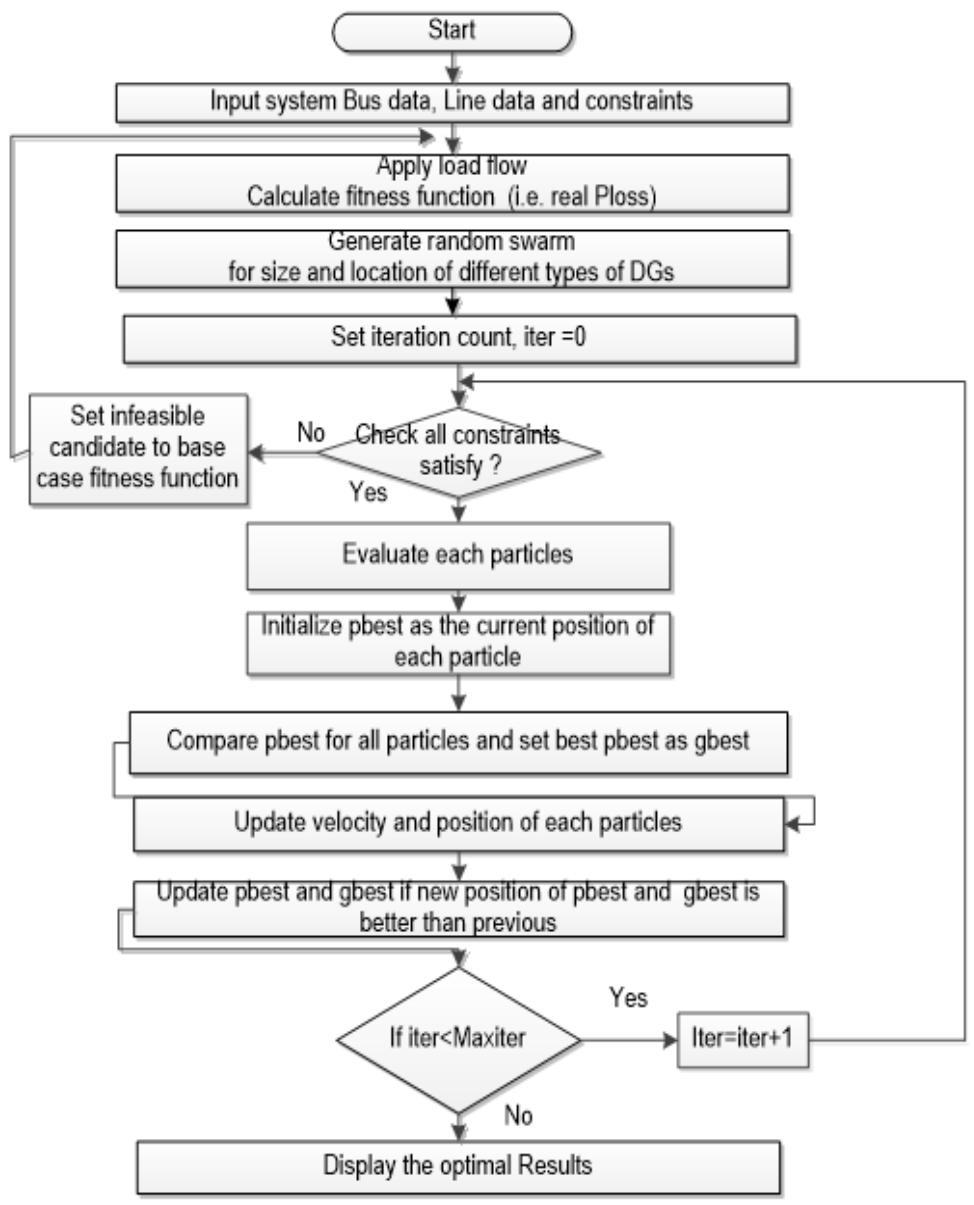

Figure 6. Flow chart for optimal DG configuration using single objective PSO optimization method

Two case studies were performed for the proposed work. For case I, different numbers of wind turbines were connected on only one bus of the system, the best bus would be selected by PSO, and for case II, the same number of wind farms were connected on two buses of the system. The following are details of the case studies.

Base case: The system's losses before installing wind farms were noted as $211 \mathrm{~kW}$ and $143 \mathrm{KVAr}$, respectively and the minimum voltage profile was observed at bus no. 18 and the maximum voltage at slack bus no. 1 of the distribution system.

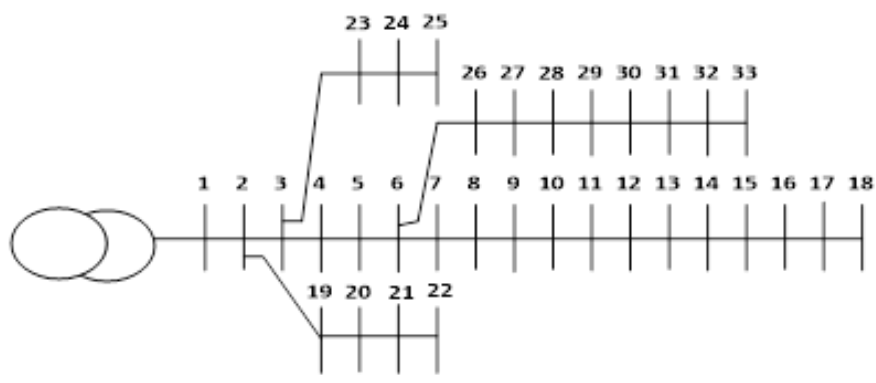

Figure 7. IEEE 33 radial distribution system 
Case I: The main purpose of this research was to reduce power losses and improve the voltage profile of the system. It was observed from the study that less numbers of wind farms would not increase voltage profile as the minimum standard voltage was 0.95 volts $( \pm 10 \%)$ and more numbers of wind farms would reduce power losses. Hence this study used four, five, and six wind turbines as shown in Table 2 . It was observed that best results were obtained when using five wind farms at bus no. 6

Case II: The same number of wind farms as in case I were separated into two and added on two buses of the system as shown in Table 2. Consequently, the best results were performed by four wind farms on bus 11 and bus 29, respectively. So it can be concluded that the same number of wind farms at two buses provided more reduction in power losses and also voltage profile improvement as compared to four wind farms on one bus.

Table 2. Power loss before and after wind farm placement

\begin{tabular}{|c|c|c|c|c|c|}
\hline \multirow{2}{*}{$\begin{array}{l}\text { No. of wind } \\
\text { farm }\end{array}$} & \multirow{2}{*}{$\begin{array}{l}\text { Wind farm } \\
\text { location }\end{array}$} & \multirow[t]{2}{*}{ Ploss (kW) } & \multirow[t]{2}{*}{ Qloss (KVar) } & \multicolumn{2}{|c|}{ Voltage (p.u) } \\
\hline & & & & Min & $\operatorname{Max}$ \\
\hline Base case & -- & 211 & 143 & 0.9037@Bus 18 & 1.0@ Slack bus \\
\hline \multicolumn{6}{|c|}{ Case I } \\
\hline 4 & Bus 6 & 112.6 & 82.3 & 0.9375@Bus 18 & 1.0@Slack bus \\
\hline 5 & Bus 6 & 111.7 & 82.2 & 0.9454@Bus 18 & 1.0@Slack bus \\
\hline 6 & Bus 7 & 124.5 & 103.6 & 0.9568@Bus 18 & 1.0@Slack bus \\
\hline \multicolumn{6}{|c|}{ Case II } \\
\hline $4(2+2)$ & Bus 11, Bus29 & 91.9 & 63.7 & 97.18@Bus 18 & 1.0@Slack bus \\
\hline $5(2+3)$ & Bus 10, Bus 27 & 100.7 & 71.0 & 96.43@Bus 18 & 1.0@Slack bus \\
\hline $6(3+3)$ & Bus 8, Bus 24 & 104.8 & 74.9 & 0.9480@Bus 18 & 1.0@ Slack bus \\
\hline
\end{tabular}

Table 3. Power Loss Before and After DG Placement

\begin{tabular}{|c|c|c|c|c|c|c|c|c|}
\hline \multirow{2}{*}{$\begin{array}{c}\text { Test } \\
\text { system }\end{array}$} & \multirow{2}{*}{ Methods } & \multicolumn{2}{|c|}{$\begin{array}{l}\text { Base case } \\
\text { Power loss }\end{array}$} & \multirow{2}{*}{$\begin{array}{c}\text { DG size } \\
\text { Type-1 MW } \\
\text { Type-2 MVar }\end{array}$} & \multicolumn{2}{|c|}{$\begin{array}{c}\text { After DG } \\
\text { Power loss }\end{array}$} & \multicolumn{2}{|c|}{ Loss reduction } \\
\hline & & $\begin{array}{l}\text { Ploss } \\
(\mathrm{kW})\end{array}$ & $\begin{array}{l}\text { Qloss } \\
\text { (KVar) }\end{array}$ & & Ploss $(\mathrm{kW})$ & $\begin{array}{l}\text { Qloss } \\
\text { (KVar) }\end{array}$ & $\begin{array}{c}\text { Ploss } \\
(\%)\end{array}$ & $\begin{array}{c}\text { Qloss } \\
(\%)\end{array}$ \\
\hline \multirow{3}{*}{ (DG) } & PSO & & & $2.6000 @$ bus 6 & 111.0 & 86.4 & 47.39 & 39.58 \\
\hline & GSA (24) & 211 & 143 & 2.6005@bus 6 & 111.0 & -- & --- & -- \\
\hline & AM (23) & & & $2.600 @$ bus 6 & 111.0 & --- & --- & --- \\
\hline
\end{tabular}

The validity of the proposed method for optimal placement and sizing of the DG in radial distribution system with PSO techniques were also compared with others, like analytical method and grid search algorithm. The results are presented in Table 3. Hence it can be concluded that the proposed method was correct and provided the similar results.

\section{CONCLUSION}

This paper presents the assessment of wind energy output from wind turbines as distributed generations. The wind data was gathered from an area in Pakistan. Data was further explored to build different wind farm capacities. The output power of these wind farms was added into the distribution system in order to reduce power losses and improve voltage profile of the system. The optimal location for the wind farm was pinpointed using PSO optimization technique. The validity of the proposed model was also compared with other optimization techniques. On the whole, it can be concluded that the proposed method provided better results.

\section{ACKNOWLEDGEMENTS}

The authors are grateful to Universiti Teknologi PETRONAS, Malaysia for technical and financial help for this research.

\section{REFERENCES}

[1] R. Viral and D. Khatod, "Optimal planning of distributed generation systems in distribution system: A review," Renewable and Sustainable Energy Reviews, vol. 16, pp. 5146-5165, 2012. 
[2] P. Paliwal, N. Patidar, and R. Nema, "Planning of grid integrated distributed generators: A review of technology, objectives and techniques," Renewable and Sustainable Energy Reviews, vol. 40, pp. 557-570, 2014.

[3] W.-S. Tan, M. Y. Hassan, M. S. Majid, and H. Abdul Rahman, "Optimal distributed renewable generation planning: A review of different approaches," Renewable and Sustainable Energy Reviews, vol. 18, pp. 626-645, 2013.

[4] R. Katyal, S. Gomathinayagam, S. Ahmed, and S. Akhtar, "Wind variability study for a complex wind farm site in India," Indian Journal of Science and Technology, vol. 3, pp. 1043-1047, 2010.

[5] D. L. Elliott, Dominican Republic Wind Energy Resource Atlas Development: National Renewable Energy Laboratory, 1999.

[6] A. Garrad, "Wind energy in Europe: A plan of action," Summary report of wind energy in Europe. Time for action. Brussels: European Wind Energy Association, 1991.

[7] Z. Liao, "The evolution of wind energy policies in China (1995-2014): An analysis based on policy instruments," Renewable and Sustainable Energy Reviews, vol. 56, pp. 464-472, 4// 2016.

[8] P. Chiradeja and R. Ramakumar, "Voltage profile improvement with distributed wind turbine generation-a case study," in Power Engineering Society General Meeting, 2003, IEEE, 2003.

[9] N. Roy, H. Pota, M. Mahmud, and M. Hossain, "Impacts of Distributed Wind Generation on Distribution Networks," in Proc. 48th Annual Conference of the Australian Solar Energy Society (AuSES), Solar, 2010.

[10] Y.-S. Jeong, S.-H. Lee, K.-H. Han, D. Ryu, and Y. Jung, "Design of short-term forecasting model of distributed generation power for solar power generation," Indian Journal of Science and Technology, vol. 8, pp. 261-270, 2015.

[11] N. Roy, M. Mahmud, and H. R. Pota, "Impact of high wind penetration on the voltage profile of distribution systems," in North American Power Symposium (NAPS), 2011, 2011, pp. 1-6.

[12] K. Zou, A. P. Agalgaonkar, K. Muttaqi, S. Perera, and N. Browne, "Support of distribution system using distributed wind and PV systems," in Power Engineering Conference, 2009. AUPEC 2009. Australasian Universities, 2009, pp. 1-6.

[13] V. Mendez, J. Rivier, J. De La Fuente, T. Gomez, J. Arceluz, J. Marin, et al., "Impact of distributed generation on distribution investment deferral," International Journal of Electrical Power \& Energy Systems, vol. 28, pp. 244-252, 2006.

[14] D. Q. Hung, N. Mithulananthan, and R. Bansal, "Analytical strategies for renewable distributed generation integration considering energy loss minimization," Applied Energy, vol. 105, pp. 75-85, 2013.

[15] A. Keane and M. O'Malley, "Optimal utilization of distribution networks for energy harvesting," Power Systems, IEEE Transactions on, vol. 22, pp. 467-475, 2007.

[16] A. Keane and M. O'Malley, "Optimal allocation of embedded generation on distribution networks," Power Systems, IEEE Transactions on, vol. 20, pp. 1640-1646, 2005.

[17] P. Farhadi, H. Shayeghi, T. Sojoudi, and M. Karimi, "Customer reliability improvement and power loss reduction in distribution systems using distributed generations," Indian Journal of Science and Technology, vol. 5, pp. 23132317, 2012.

[18] Y. Atwa and E. El-Saadany, "Probabilistic approach for optimal allocation of wind-based distributed generation in distribution systems," IET Renewable Power Generation, vol. 5, pp. 79-88, 2011.

[19] Y. Atwa, E. El-Saadany, M. Salama, and R. Seethapathy, "Optimal renewable resources mix for distribution system energy loss minimization," Power Systems, IEEE Transactions on, vol. 25, pp. 360-370, 2010.

[20] M. Haque, "Efficient load flow method for distribution systems with radial or mesh configuration," IEE Proceedings-Generation, Transmission and Distribution, vol. 143, pp. 33-38, 1996.

[21] S. F. Khahro, K. Tabbassum, A. M. Soomro, X. Liao, M. B. Alvi, L. Dong, et al., "Techno-economical evaluation of wind energy potential and analysis of power generation from wind at Gharo, Sindh Pakistan," Renewable and Sustainable Energy Reviews, vol. 35, pp. 460-474, 2014.

[22] T. Yamamoto and Y. Ishida, Linear and nonlinear rotordynamics: A modern treatment with applications vol. 11: John Wiley \& Sons, 2001.

[23] Kennedy J. Particle swarm optimization. Encyclopedia of Machine Learning: Springer; 2010, pp. 760-6.

[24] S. Kansal, V. Kumar, and B. Tyagi, "Optimal placement of different type of DG sources in distribution networks," International Journal of Electrical Power \& Energy Systems, vol. 53, pp. 752-760, 2013.

[25] S. Kansal, V. Kumar, and B. Tyagi, "Composite active and reactive power compensation of distribution networks," in Industrial and Information Systems (ICIIS), 2012 7th IEEE International Conference on, 2012, pp. 1-6. 